\title{
MODELLING OF A TEMPORARY TEMPERATURE FIELD DURING ARC WELD SURFACING OF STEEL ELEMENTS TAKING INTO ACCOUNT HEAT OF THE WELD
}

\author{
Jerzy Winczek ${ }^{1}$, Grażyna Rygat ${ }^{2}$ \\ ${ }^{I}$ Faculty of Mechanical Engineering and Computer Science, Czestochowa University of Technology \\ Czestochowa, Poland \\ ${ }^{2}$ Pedagogical Faculty, Jan Dlugosz University in Czestochowa, Poland \\ winczek@gmail.com,g.rygal@ajd.czest.pl
}

\begin{abstract}
In this work, a model of a temperature field in a steel element during a singlepass arc weld surfacing is presented. Analytical solution for half-infinite body model is obtained by aggregating temperature increments caused by applying liquid metal and heat radiation of a moving electrode. The assumptions are Gaussian distributed heat sources of applied metal and the weld and of an electric arc heat source. Computations of the temperature field were carried out during arc weld surfacing of cuboidal steel element. The results are presented as temporary and maximum temperature distribution in the element's crosssection and thermal cycles at selected points. The accuracy of the solution is verified comparing a calculated fusion line to that obtained experimentally.
\end{abstract}

Keywords: modeling, arc weld surfacing, temperature field

\section{Introduction}

In the modeling of a temperature field of welding processes, a single-distributed heat source model is generally assumed, reflecting the direct impact of the electric arc on the surfacing object. This approach is found in the description of the temperature field during welding processes using analytical and numerical methods [1-7]. The shape of the fusion lines during arc weld surfacing exhibit shape irregularity, which is difficult to restore by means of the description of the temperature field obtained by using the analytical method and the single-distributed heat source model.

Jeong and Cho [8] proposed taking into account the area of melted metal in fillet weld by summing up a bivariate Gaussian distributed heat source. Analogically, Kang and Cho [9] solved the temperature field in the welding model using GTA (Gas Tungsten Arc) method taking into consideration filler wire.

Arc weld surfacing is distinguished by applying liquid metal (in some cases up to 20 millimeters thick), which spills across the surface and constitutes an addition- 
al heat source. Analyses of metallographic specimens of surfaced elements [10] indicate that fusion lines have more irregular shapes than in the case of welding, due to liquid metal spilling across the surface of the welded element. The necessity of taking into consideration the heat of melted metal in temperature field solutions in arc weld surfacing processes is therefore essential, which is presented in this work.

\section{Analytical solution of temperature field during arc weld surfacing}

The description of the temperature field is summing temperature fields caused by the heat of direct impact of an electric arc and the heat transferred to the surfaced object through the molten electrode material This allows the formulation of the temperature field in the form:

$$
T(x, y, z, t)-T_{0}=\sum_{i=1}^{2} \Delta T_{i}
$$

where: $\Delta T_{1}$ and $\Delta T_{2}$ are temperature accruals caused by the heat of liquid metal of weld and electric arc respectively.

The analytical description of the above-mentioned field is obtained using the heat conduction equation in a fixed Cartesians coordinate system $(x, y, z)$ :

$$
\nabla(\lambda \nabla T)+q=C_{p} \rho \frac{\partial T}{\partial t}
$$

where: $C_{p}$ - specific heat $[\mathrm{J} / \mathrm{kg} \mathrm{K}], \rho$ - density $\left[\mathrm{kg} / \mathrm{m}^{3}\right], \lambda$ - coefficient of heat conduction $[\mathrm{W} / \mathrm{m} \mathrm{K}]), T$ - temperature, $t$ - time,

which for infinite body with temporary heat source $q$ applied at arbitrary point of body with coordinates $\left(x^{\prime}, y^{\prime}, z^{\prime}\right)$ takes the following form [11]:

$$
T(x, y, z, t)=\frac{q}{C_{p} \rho(4 \pi a t)^{1.5}} \exp \left(-\frac{\left(x-x^{\prime}\right)^{2}+\left(y-y^{\prime}\right)^{2}+\left(z-z^{\prime}\right)^{2}}{4 a t}\right)
$$

with the following conditions:

$$
\begin{aligned}
& T(x, y, z, 0)=T_{0} \\
& \frac{\partial T}{\partial x}=\frac{\partial T}{\partial y}=0 \text { for } x, y \rightarrow \pm \infty \\
& \frac{\partial T}{\partial z}=0 \text { for } z \rightarrow \pm \infty \\
& \left.\frac{\partial T}{\partial z}\right|_{z=0}=0
\end{aligned}
$$

where $a$ - thermal diffusivity $\left[\mathrm{m}^{2} / \mathrm{s}\right]$. 
Based on this solution for point source and solutions for planar source [12], an analytical description of temperature field in semi-infinite body for singular volumetric heat source (Fig. 1) was formulated in the works [13, 14].

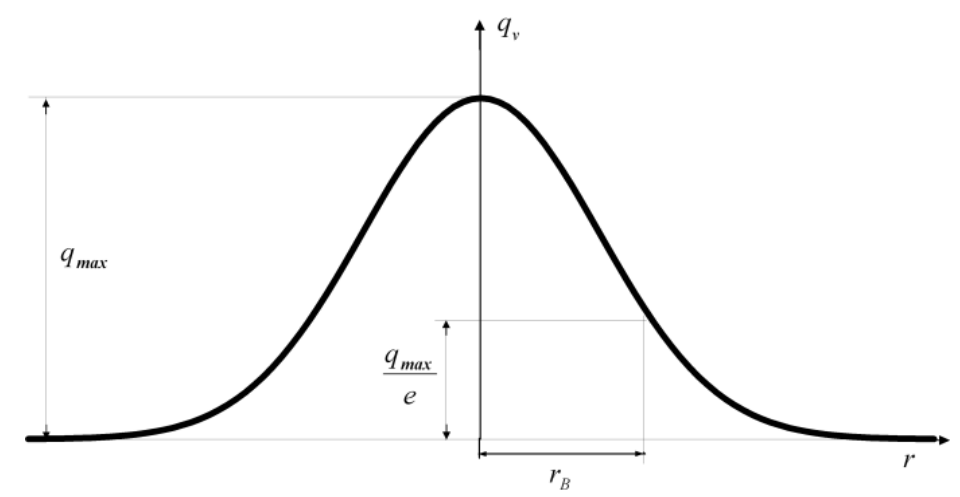

Fig. 1. Gaussian distribution of volumetric heat source

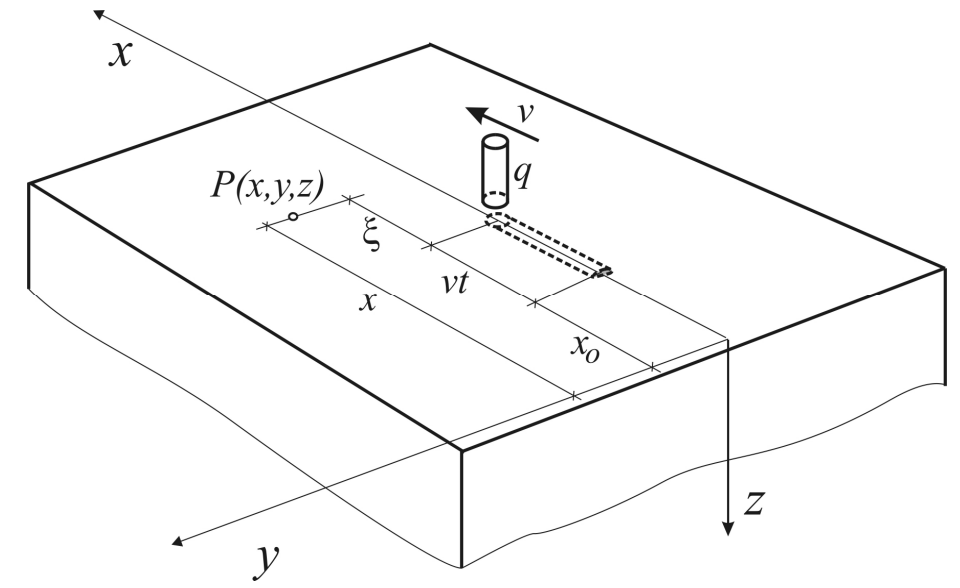

Fig. 2. The scheme of single-pass surfacing

According to that solution and Eq. (2) increase of temperature at point $P$ with coordinates $(x, y, z) \xi$ meters away from source (Fig. 2) can be described by: - for time $t \leq t_{c}$, where $t_{c}$ means total time of creating the weld:

$$
\Delta T_{i}=A_{i}^{H} \int_{0}^{t} F_{i}^{H}\left(t^{\prime \prime}\right) d t^{\prime \prime}
$$

- for time $t>t_{c}$ :

$$
\Delta T_{i}=A_{i}^{C} \int_{0}^{t_{c}} F_{i}^{C}\left(t^{\prime}\right) d t^{\prime}
$$


where:

$$
\begin{aligned}
& A_{i}^{H}=\frac{3}{16} \frac{\dot{q}_{i}}{C_{p} \rho \pi a z_{0 i}} \exp \left(-\frac{v \xi}{2 a}-\frac{v^{2} t_{0 i}}{4 a}\right) \\
& A_{i}^{C}=\frac{3}{16} \frac{\dot{q}_{i}}{C_{p} \rho \pi a z_{0 i}} \\
& F_{C}\left(t^{\prime}\right)=\frac{1}{t+t_{0 i}-t^{\prime}} \exp \left(-\frac{\left(x-v t^{\prime}-x_{0}\right)^{2}+\left(y-y_{0}\right)^{2}}{4 a\left(t+t_{0 i}-t^{\prime}\right)}\right) \\
& \left\{\left(\left(1-\frac{z^{2}+2 a\left(t-t^{\prime}\right)}{z_{0 i}^{2}}\right) \operatorname{erf}\left(\frac{z+z_{0 i}}{2\left(a\left(t-t^{\prime}\right)\right)^{0.5}}\right)+\right.\right. \\
& \left.-\Phi(z) \operatorname{erf}\left(\Phi(z) \frac{z-z_{0 i}}{2\left(a\left(t-t^{\prime}\right)\right)^{0.5}}\right)\right)+ \\
& +\frac{4 a\left(t-t^{\prime}\right)}{z_{0 i}^{2}}\left(\frac{z+z_{0 i}}{2\left(\pi a\left(t-t^{\prime}\right)\right)^{0.5}} \exp \left(-\frac{\left(z-z_{0 i}\right)^{2}}{4 a\left(t-t^{\prime}\right)}\right)+\right. \\
& \left.\left.-\frac{z-z_{0 i}}{2\left(\pi a\left(t-t^{\prime}\right)\right)^{0.5}} \exp \left(-\frac{\left(z+z_{0 i}\right)^{2}}{4 a\left(t-t^{\prime}\right)}\right)\right)\right\} \\
& F_{H}\left(t^{\prime \prime}\right)=\frac{1}{t^{\prime \prime}+t_{0 i}} \exp \left(-\frac{\xi^{2}}{4 a\left(t^{\prime \prime}+t_{0 i}\right)}-\frac{v^{2} t^{\prime \prime}}{4 a}\right)\left\{( 1 - \frac { z ^ { 2 } + 2 a t ^ { \prime \prime } } { z _ { 0 i } ^ { 2 } } ) \left(\operatorname{erf}\left(\frac{z+z_{0 i}}{2\left(a t^{\prime \prime}\right)^{0.5}}\right)+\right.\right. \\
& \left.-\Phi(z) \operatorname{erf}\left(\Phi(z) \frac{z-z_{0 i}}{2\left(a t^{\prime \prime}\right)^{0.5}}\right)\right)+\frac{4 a t^{\prime \prime}}{z_{0 i}^{2}}\left(\frac{z+z_{0 i}}{2\left(\pi a t^{\prime \prime}\right)^{0.5}} \exp \left(-\frac{\left(z-z_{0 i}\right)^{2}}{4 a t^{\prime \prime}}\right)\right. \\
& \left.\left.-\frac{z-z_{0 i}}{2\left(\pi a t^{\prime \prime}\right)^{0.5}} \exp \left(-\frac{\left(z+z_{0 i}\right)^{2}}{4 a t^{\prime \prime}}\right)\right)\right\} d t^{\prime \prime} \\
& \Phi(z)=\left\{\begin{array}{rll}
-1 & \text { for } & z \in<0, z_{0 i}> \\
1 & \text { for } & z \in\left(z_{0 i}, \infty\right)
\end{array}\right. \\
& \dot{q}_{2}=\eta U I-\dot{q}_{1} \\
& t_{c}=l / v \\
& \xi=x-v\left(t+t_{0}\right)-x_{0}
\end{aligned}
$$


$U, I$ and $\eta$ voltage, amperage and arc efficiency respectively, $l$ length of the weld, and $v$ welding velocity (of electrode), indices $i$ by sources' parameters concern (for $i=1$ ) the heat accumulated in applied weld and (for $i=2$ ) remaining heat determined by Eq. (11), $z_{0 i}$ denotes depth of heat source depositions, while quantity $t_{0 i}$ characterizes the surface heat distribution, so that:

$$
r_{i}^{2}=4 a t_{0 i}
$$

where $r_{i}$ denotes averaged radiuses of Gaussian distributed heat sources [15].

The total amount of heat $q_{1}$ contained in the material of melted electrode is expressed by relationship [16]:

$$
q_{1}=\Delta q_{\text {solid }}+\Delta q_{f}+\Delta q_{\text {liquid }}
$$

where:

$\Delta q_{\text {solid }}$ - heat necessary to heatup the electrode from initial temperature to melting temperature

$$
\Delta q_{\text {solid }}=m C_{p}\left(T_{S}-T_{e}\right)
$$

$\Delta q_{f}$ - heat used for melting the electrode (heat of fusion)

$$
\Delta q_{f}=m L
$$

$\Delta q_{\text {liquid }}$ - heat used for heatingup melted material to the temperature in which the drop of metal falls on the surface of welded material

$$
\Delta q_{\text {liquid }}=m C_{p}\left(T_{L}-T_{S}\right)
$$

Then Eq. (15) is:

$$
q_{1}=m C_{p}\left(T_{S}-T_{e}\right)+m C_{p}\left(T_{L}-T_{S}\right)+m L
$$

The initial temperature of electrode $T_{e}$ from the welding head is set at $373 \mathrm{~K}$. On account of this and differentiating Eq. (19) with respect to time:

$$
\dot{q}_{1}=\dot{m}\left(C_{p}\left(T_{L}-T_{e}\right)+L\right)
$$

where:

$$
\dot{m}=\rho_{e} \frac{\pi d^{2}}{4} v_{e}
$$

$v_{e}[\mathrm{~m} / \mathrm{s}]$ - velocity of passing electrode wire with diameter $d[\mathrm{~m}]$ and density $\rho_{e}$ $\left[\mathrm{kg} / \mathrm{m}^{3}\right], T_{L}$ - temperature of liquid metal applied on welded surface $[\mathrm{K}]$ and $T_{S}$ solidus temperature $[\mathrm{K}]$. 
The face of weld is determined mainly by surface tension forces. Based on experimental researches, Hrabe et al. [17] proposed the parabolic shape of the face of weld, which has been applied in this work.

\section{Example of computations}

Computations of time- and spatially-varying changeable temperature field for steel element in a shape of side of length $0.4 \mathrm{~m}$ and width $0.4 \mathrm{~m}$ made from steel S235 have been conducted. The calculations were performed using the authorial program created in the Borland Delphi environment. Thermal properties of welded subject material and an electrode have been determined by $a=8 \cdot 10^{-6} \mathrm{~m}^{2} / \mathrm{s}, C_{p}=$ $=670 \mathrm{~J} / \mathrm{kg} \mathrm{K}, \rho=7800 \mathrm{~kg} / \mathrm{m}^{3}, L=268 \mathrm{~kJ} / \mathrm{kg}$ and $T_{S}=1766 \mathrm{~K}$.

Numerical simulations of temperature field have been made while applying weld $0.2 \mathrm{~m}$ long in the middle part of the plate (initial coordinate of weld $x_{0}=$ $=0.1 \mathrm{~m}$ ). The volumetric heat sources with Gaussian distribution of power density distinguished by $z_{01}=0.0005 \mathrm{~m}, t_{01}=4.5 \mathrm{~s}$ and $z_{02}=0.009 \mathrm{~m}, t_{02}=0.1 \mathrm{~s}$. The sum of heat powers corresponds to welding parameters $(U=24.3 \mathrm{~V}, I=232 \mathrm{~A}, \eta=0.6)$ used in welding trials using GMA (Gas Metal Arc) method conducted by Klimpel et al. [10]. Likewise in the experiment, in calculations were assumed welding velocity $v=0.007 \mathrm{~m} / \mathrm{s}$, electrode wire diameter $d=1.2 \mathrm{~m}$, wire feed speed $v_{e}=$ $=0.013 \mathrm{~m} / \mathrm{s}$ and bead dimensions $h_{w}=2.77 \mathrm{~mm}$ and $w_{w}=11.93 \mathrm{~mm}$. The initial temperature of liquid metal applied on the surface of cast was assumed at $T_{L}=$ $=2773 \mathrm{~K}$.

The analysis of the temperature field in middle cross-section of surfaced steel cast has been conducted. In Figures 3-6 temperature distributions are presented during surfacing: $0.5 \mathrm{~s}$ before (Fig. 3) and $0.5 \mathrm{~s}$ (Fig. 4), and $4 \mathrm{~s}$ (Fig. 5) after passage of electrode and application of weld.

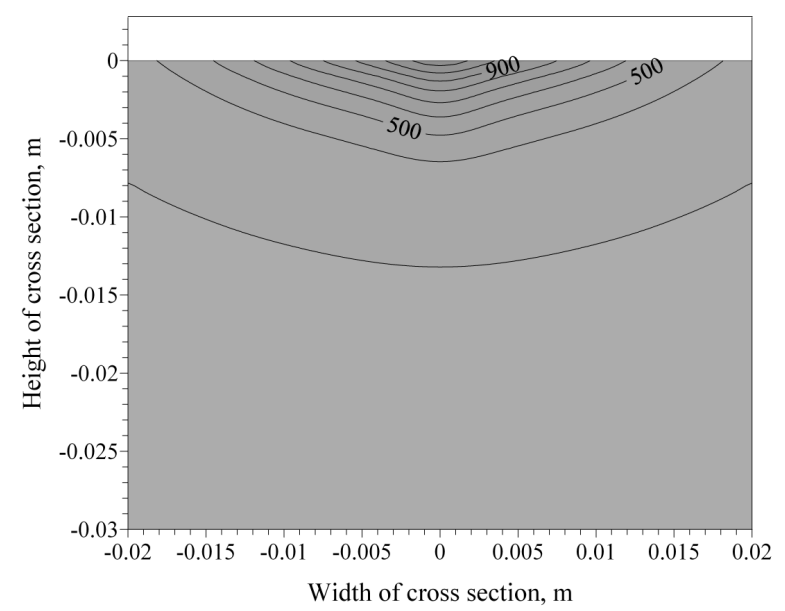

Fig. 3. Temperature field $0.5 \mathrm{~s}$ before the passage of electrode 


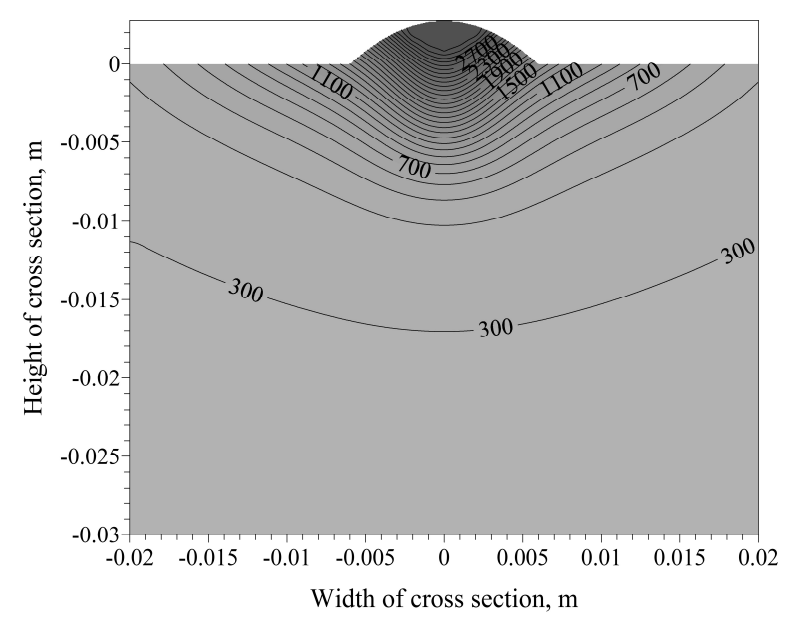

Fig. 4. Temperature field $0.5 \mathrm{~s}$ after the passage of electrode

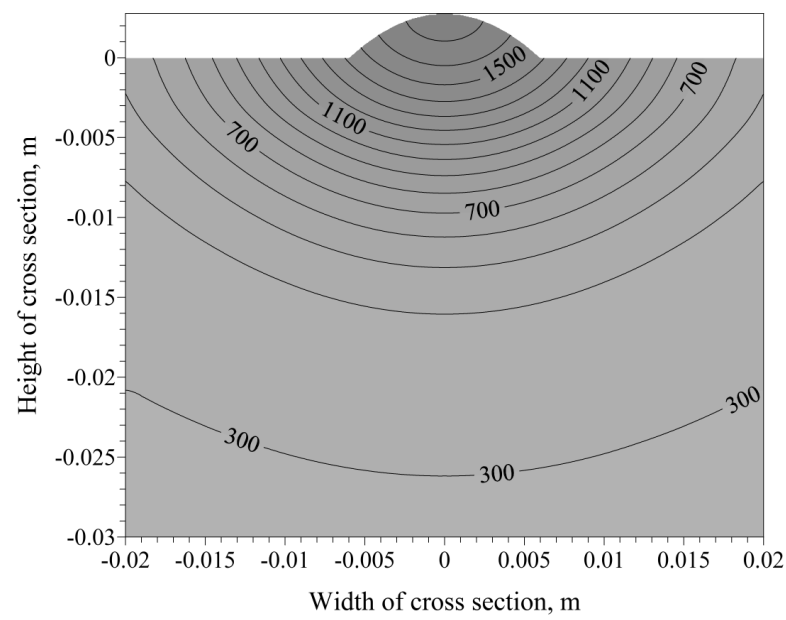

Fig. 5. Temperature field $4 \mathrm{~s}$ after the passage of electrode

Figure 6 in turn presents maximum temperatures in cross-section. Temperature distribution on the surface of surfaced steel cast after $25 \mathrm{~s}$ of surfacing $(10 \mathrm{~s}$ after passage above middle cross-section $-x=0.1 \mathrm{~m}$ ) is presented in Figure 7.

The maximum temperature field in cross section allows one to determine the heat affected zone. Figure 8 presents heat affected zones determined by the initial $A_{1}=993 \mathrm{~K}$ and final $A_{3}=1108 \mathrm{~K}$ temperature of austenitic transformation as well as fusion line $1766 \mathrm{~K}$. Fusion line (solidification temperature of steel) in this figure corresponds to fusion line obtained in experiment described by Klimpel et al. [10]. The suggested temperature field model enables one to calculate welding thermal cycle in any point of cross section. Thermal cycles at selected points of crosssection (cf. Fig. 8) are presented in Figure 9. 


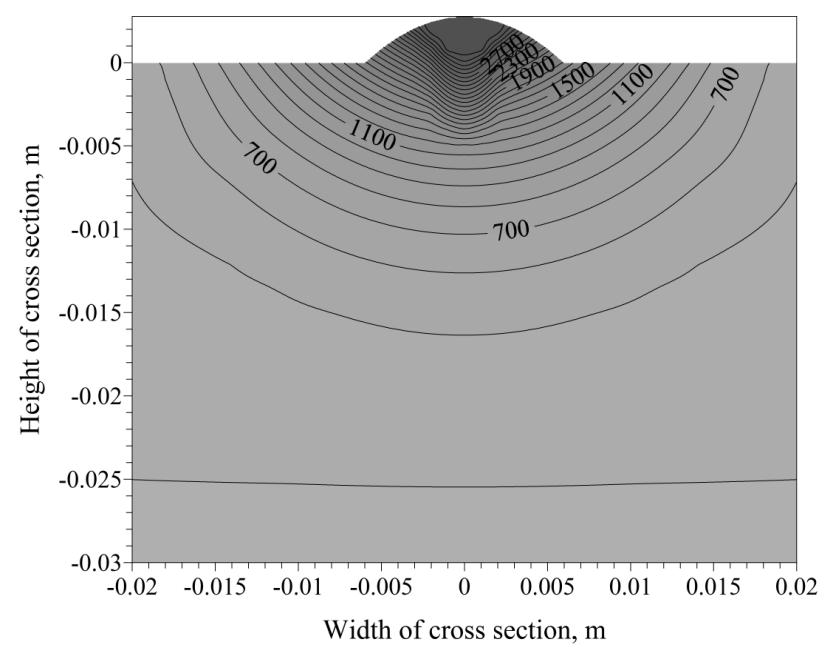

Fig. 6. Maximum temperature field

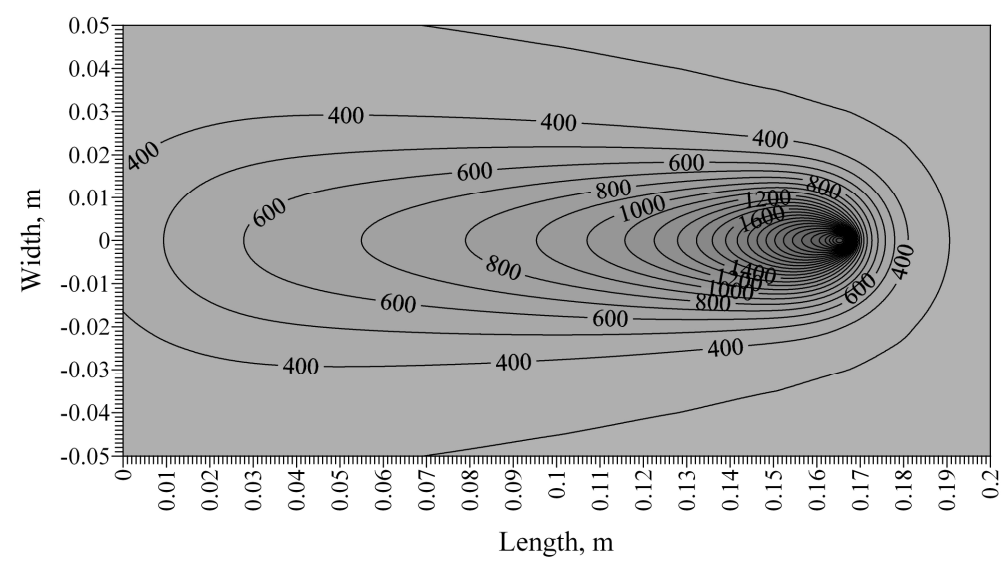

Fig. 7. Temperature isolines on the surface of arc weld surfaced steel element after $25 \mathrm{~s}$ of surfacing begin

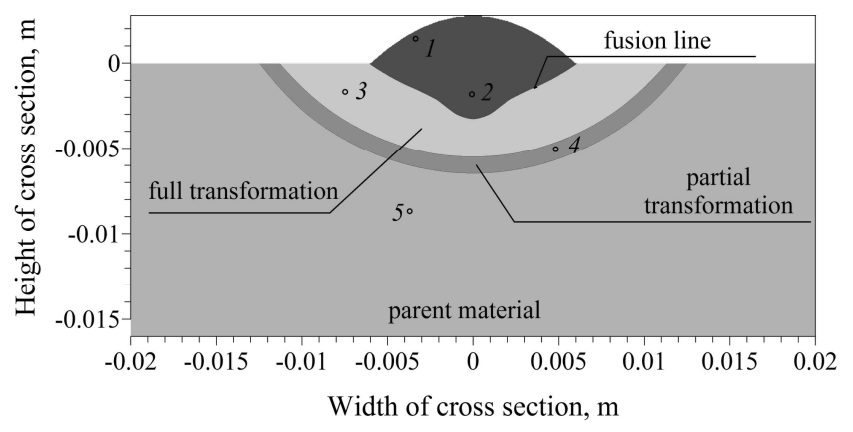

Fig. 8. Heat affected zone with selected points 


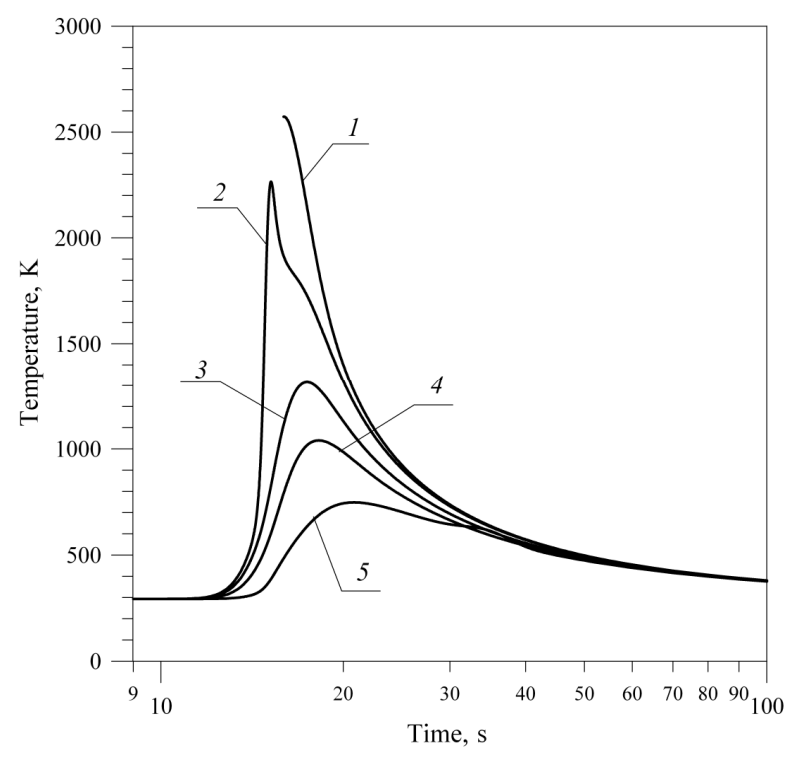

Fig. 9. Thermal cycles at selected points of cross-section

\section{Conclusions}

Surfacing is distinguished by application of liquid metal, which spills across the surface and creates an additional heat source. Consideration of this heat source is therefore essential in temperature field solutions. In this work, a temperature field solution of surfacing for a half-infinite body model is presented. The solution is obtained by aggregating temperature accruals caused by applying liquid metal and thermal radiation from a moving electrode. As a comparative criterion of numerical simulations and experimental research results, the shape and measurements of fusion line were assumed. The accuracy of the solution was confirmed by comparison of a calculated fusion line with that obtained experimentally by other authors with the same technological parameters of the process.

The presented model enables the determination of heat affected zone (HAZ), including partial and full transformations and fusion zones, as well as analysis of thermal cycles at any point of the steel cast. The results of numerical simulations indicate a significant influence the heat of weld has on temperature distribution in fusion and full transformation zones.

\section{References}

[1] Parkitny R., Pawlak A., Piekarska W., Thermal model of submerged arc welding process, Mat. Science Technol. 1992, 8, 841-843.

[2] Lindgren L.E., Computational Welding Mechanics. Thermomechanical and Microstructural Simulations, Woodhead Publishing Ltd., Cambridge 2007. 
[3] Nguyen N.T., Thermal Analysis of Welds, WITPress, Southampton, Boston 2004.

[4] Goldak J.A., Akhlaghi M., Computational Welding Mechanics, Springer, New York 2010.

[5] Piekarska W., Kubiak M., Theoretical investigations into heat transfer in laser-welded steel sheets, J. Them. Anal. Calorim 2012, 110, 159-166.

[6] Joshi S., Hildebrand J., Aloraier A.S., Rabczuk T., Characterization of material properties and heat source parameters in welding simulation of two overlapping beads on a substrate plate, Comp. Mater. Sci. 2013, 69, 559-565.

[7] Ghosh A., Barman N., Chattopadhyay H., Hloch S., A study of thermal behaviour during submerged arc welding, Strojniški vestnik - J. Mech. Eng. 2013, 59(5), 333-338.

[8] Jeong S.K., Cho H.S., An analytical solution for transient temperature distribution in fillet arc welding including the effect of molten metal, Proceedings of Institution of Mechanical Engineers, Journal of Engineering Manufacture 1997, 211B, 63-72.

[9] Kang S.H., Cho H.S., Analytical solution for transient temperature distribution in gas tungsten arc welding with consideration of filler wire, Proceedings of Institution of Mechanical Engineers. J. Eng. Manuf. 1999, 213B, 799-811.

[10] Klimpel A., Balcer M., Klimpel A.S., Rzeźnikiewicz A., The effect of the method and parameters in the GMA surfacing with solid wires on the quality of pudding welds and the content of the base material in the overlay, Weld. Int. 2006, 11, 845-850.

[11] Radaj D., Heat Effects of Welding. Temperature Field, Residual Stress, Distortion, Springer-Verlag, Berlin, Heidelberg, New York, London, Paris, Tokyo 1992.

[12] Easterling K.E., Modelling the weld thermal cycle and transformation behaviour in the heat affected zone, [in:] Mathematical Modelling of Weld Phenomena, eds. H.K.E. Cerjak, K.R. Easterling, The Institute of Materials, London 1993.

[13] Winczek J., Analytical solution to transient temperature field in a half-infinite body caused by moving volumetric heat source, Int. J. Heat Mass Transfer 2010, 53, 5774-5781.

[14] Winczek J., Modelling of heat affected zone in cylindrical steel elements surfaced by welding, Appl. Math. Model. 2012, 36, 1514-1528.

[15] Vishnu P.R., Li W.B., Easterling K.E., Heat-flow model for pulsed welding, Mat. Sci. Technol. 1991, 7, 649-659.

[16] Modenesi P.J., Reis R.I., A model for melting rate phenomena in GMA welding, J. Mater. Proc. Technol. 2007, 189, 199-205.

[17] Hrabe P., Choteborsky R., Navratilova M., Influence of welding parameters on geometry of weld deposit bead, Int. Conf. Economic Eng. Manuf. Systems, Brasov, 26-27 November 2009, Regent, 10, 3(27), 291-294. 